\title{
Survivin Is a Transcriptional Target of STAT3 Critical to Estradiol Neuroprotection in Global Ischemia
}

\author{
Yoshihide Sehara, Kirsty Sawicka, Jee-Yeon Hwang, Adrianna Latuszek-Barrantes, Anne M. Etgen, \\ and R. Suzanne Zukin \\ Dominick P. Purpura Department of Neuroscience, Albert Einstein College of Medicine, Bronx, New York 10461
}

\begin{abstract}
Transient global ischemia causes selective, delayed death of hippocampal CA1 pyramidal neurons in humans and animals. It is well established that estrogens ameliorate neuronal death in animal models of focal and global ischemia. However, the role of signal transducer and activator of transcription-3 (STAT3) and its target genes in estradiol neuroprotection in global ischemia remains unclear. Here we show that a single intracerebral injection of $17 \beta$-estradiol to ovariectomized female rats immediately after ischemia rescues CA1 neurons destined to die. Ischemia promotes activation of STAT3 signaling, association of STAT3 with the promoters of target genes, and STAT3-dependent mRNA and protein expression of prosurvival proteins in the selectively vulnerable CA1. In animals subjected to ischemia, acute postischemic estradiol further enhances activation and nuclear translocation of STAT3 and STAT3-dependent transcription of target genes. Importantly, we show that STAT3 is critical to estradiol neuroprotection, as evidenced by the ability of STAT3 inhibitor peptide and STAT3 shRNA delivered directly into the CA1 of living animals to abolish neuroprotection. In addition, we identify survivin, a member of the inhibitor-of-apoptosis family of proteins and known gene target of STAT3, as essential to estradiol neuroprotection, as evidenced by the ability of shRNA to survivin to reverse neuroprotection. These findings indicate that ischemia and estradiol act synergistically to promote activation of STAT3 and STAT3-dependent transcription of survivin in insulted CA1 neurons and identify STAT3 and survivin as potentially important therapeutic targets in an in vivo model of global ischemia.
\end{abstract}

\section{Introduction}

Transient global ischemia arises as a consequence of cardiac arrest, cardiac surgery, profuse bleeding, near-drowning, and carbon monoxide poisoning and causes selective, delayed death of hippocampal CA1 pyramidal neurons and cognitive deficits in humans and animals (Liou et al., 2003; Moskowitz et al., 2010; Ofengeim et al., 2011). There are still remarkably few safe and effective treatments to reduce the neurodegeneration and cognitive dysfunction associated with global ischemia. $17 \beta$-estradiol, the primary estrogen produced and secreted by the ovaries, influences development, growth, differentiation, maturation, and function of various tissues, including brain (Blaustein, 2012; Kelly and Rønnekleiv, 2012; McEwen et al., 2012). It is well established that endogenous and exogenous estrogens exert profound neuroprotective effects in animal models of focal and global ischemia (Lebesgue et al., 2009; Etgen et al., 2011; Brann et

\footnotetext{
Received April 29, 2013; revised June 3, 2013; accepted June 21, 2013.

Author contributions: Y.S., K.S., A.M.E., and R.S.Z. designed research; Y.S., J.-Y.H., and A.L.-B. performed research;Y.S. and K.S. analyzed data; Y.S., A.M.E., and R.S.Z. wrote the paper.

This work was supported by National Institutes of Health Grant NS045693 (R.S.Z.), a generous grant from the Kirby Foundation, and the Nakayama Foundation for Human Science. R.S.Z. is the F.M. Kirby Chair in Neural Repair and Protection. We thank Dr. Kostantin Dobrenis, Director of the Cellular and Molecular Neuroimaging Core of the Rose F. Kennedy Intellectual and Developmental Disabilities Research Center, for use of the confocal microscope and technical assistance.

The authors declare no competing financial interests.

Correspondence should be addressed to Dr. R. Suzanne Zukin, Dominick P. Purpura Department of Neuroscience, Albert Einstein College of Medicine, 1300 Morris Park Avenue, Bronx, NY 10461. E-mail: suzanne.zukin@einstein.yu.edu.

DOI:10.1523/JNEUROSCI.1852-13.2013

Copyright $\odot 2013$ the authors $\quad 0270-6474 / 13 / 3312364-11 \$ 15.00 / 0$
}

al., 2012). Estradiol can afford neuroprotection when administered chronically for 1-2 weeks before ischemia or by a single (acute) injection delivered after the ischemic event. Whereas the molecular mechanisms underlying neuroprotection by chronic estradiol are well studied (Scott et al., 2012), the precise mechanisms underlying neuroprotection by acute estradiol in global ischemia are, as yet, unclear.

Signal transducer and activator of transcription-3 (STAT3) is a member of the STAT protein family of transcription factors, which coordinate and integrate signals from extracellular stimuli and play a pivotal role in growth and differentiation in a variety of cell types (Horvath, 2000; Reich and Liu, 2006). In postmitotic cells such as neurons, STAT3 is quiescent (Bromberg and Darnell, 2000), but can be activated by phosphorylation at Tyr705 in response to cytokines, growth factors, and hormones such as estradiol (Horvath, 2000). Upon phosphorylation, STAT3 dimerizes and translocates to the nucleus, where it serves as a dynamic, sensitive molecular on-off switch for transcription of target genes (Reich and Liu, 2006). STAT3 is also activated in response to injurious stimuli and may play an important role in neuronal survival (Dziennis and Alkayed, 2008). STAT3 regulates transcription of an array of prosurvival target genes such as $\mathrm{Bcl}-\mathrm{xL}, \mathrm{Bcl} 2$, manganese-containing superoxide dismutase (MnSOD), and survivin (Stephanou et al., 2000; Gritsko et al., 2006; Jung et al., 2009).

Survivin is a member of the prosurvival inhibitor-of-apoptosis protein family, which act upstream of the caspase death cascade to prevent caspase activation and downstream of caspase cleavage to bind and inhibit activated caspases, thereby halting apoptotic cell 
A
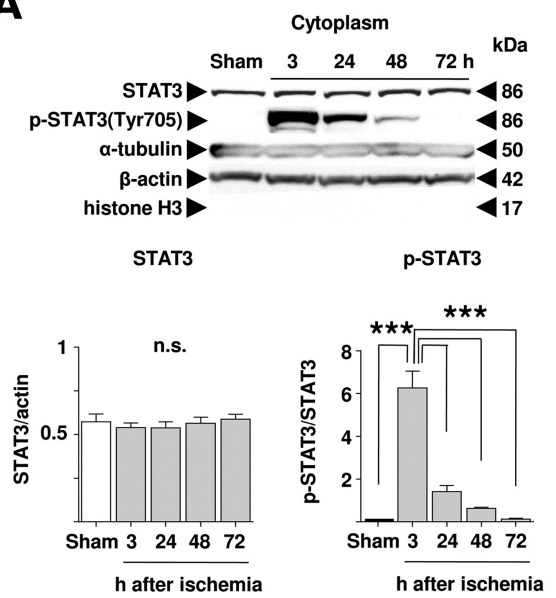

B
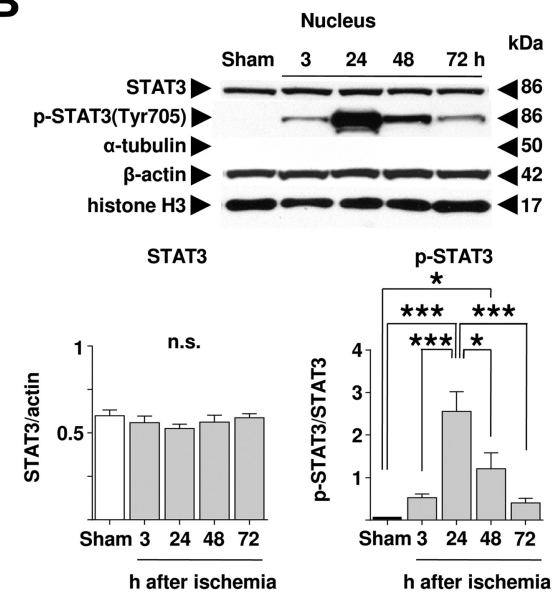

Figure 1. Global ischemia induces a marked increase in phosphorylation of STAT3 at Tyr705 in CA1. $A$, Top, Representative Westerns showing STAT3 and p-Tyr705-STAT3 in the cytoplasm of CA1 at times after global ischemia in ovariectomized female rats. Bottom, Summary data. p-Tyr705-STAT3 was maximal in the cytoplasm at $3 \mathrm{~h}$ and remained elevated as late as $48 \mathrm{~h}$ after ischemia $(n=5$ per time point). $\boldsymbol{B}$, Top, Representative Westerns showing STAT3 and p-Tyr705-STAT3 in the nucleus of CA1 at times after global ischemia. Bottom, Summary data. p-Tyr705-STAT3 was maximal in the nucleus at $24 \mathrm{~h}$, after which it declined to near control values ( $n=5$ per time point). ANOVA followed by Tukey. Data represent mean \pm SEM; ${ }^{* * *} p<0.001$; $^{*} p<0.05$. n.S., Not significant.

death (Altieri, 2008; Baratchi et al., 2010). Inhibitor-of-apoptosis proteins inhibit not only caspase-dependent but also caspaseindependent cell death (Gyrd-Hansen and Meier, 2010). Compelling data support additional roles for survivin in brain development, neurogenesis, and synaptic plasticity (Jiang et al., 2005; Coremans et al., 2010; Iscru et al., 2013). The present study was undertaken to examine the possibility that STAT3 and its downstream target survivin are key mediators of estradiol neuroprotection in the hippocampal CA1 in an in vivo model of global ischemia. The identification of potential therapeutic targets is critical for the development of novel strategies for the treatment of the neurological sequelae associated with global ischemia.

\section{Materials and Methods}

Ovariectomy and global ischemia. Six-week-old female Sprague Dawley rats weighing 150-200 g (Charles River) at the time of ischemic insult were maintained in a temperature- and light-controlled environment and were treated in accordance with the principles and procedures of the National Institutes of Health Guidelines for the Care and Use of Laboratory Animals. All protocols were approved by the Institutional Animal Care and Use Committee of the Albert Einstein College of Medicine. Two weeks after bilateral ovariectomy, animals were subjected to transient global ischemia by four-vessel occlusion ( $10 \mathrm{~min}$ ), followed by reperfusion, as described previously (Miyawaki et al., 2009). Briefly, on the day before ischemia induction, rats were anesthetized with isoflurane $(4 \%$ induction, $1.5 \%$ maintenance, $\mathrm{v} / \mathrm{v})$ in a mixture of $\mathrm{N}_{2}: \mathrm{O}_{2}(70: 30)$ delivered by a Vapomatic anesthetic vaporizer. The vertebral arteries were permanently occluded by electrocauterization, the common carotid arteries were exposed through a ventral midline neck incision and isolated with 3-0 silk ligatures, and the wound was closed. Rats were fasted overnight and anesthetized the next day. The wound was reopened, and the carotid arteries were occluded with nontraumatic aneurysm clips (10 $\mathrm{min})$. In all cases, anesthesia was discontinued immediately after initiation of occlusion. The anesthesia was initiated again just after the aneurysm clips were removed and maintained until the intracerebroventricular injections were complete (see below). After removal of clips, the arteries were visually inspected to ensure adequate flow. Body temperature was maintained at $37.5 \pm 0.5^{\circ} \mathrm{C}$ with a rectal thermostat and heat lamp until recovery from anesthesia. Animals that failed to recover within 30 min were excluded from the study $(\sim 4 \%)$. Animals that failed to show complete loss of the righting reflex and dilatation of the pupils 2 min after occlusion was initiated until the end of occlusion, and those few animals that subsequently exhibited obvious behavioral manifestations (abnormal vocalization when handled, generalized convulsions, loss of $>20 \%$ body weight, or hypoactivity) were excluded $(\sim 6 \%)$.

Estradiol and STAT3 inhibitor administration. Drugs were administered immediately upon reperfusion by intracerebroventricular injection. For intracerebroventricular injection, under isoflurane anesthesia, a 34 gauge needle attached to a Hamilton syringe was stereotaxically lowered into the right lateral ventricle to a position defined by the following coordinates relative to bregma: $0.92 \mathrm{~mm}$ posterior, $1.2 \mathrm{~mm}$ lateral, 3.6 $\mathrm{mm}$ below the skull surface as described previously (Jover-Mengual et al., 2010). A total of $5 \mu \mathrm{l}$ was injected at a rate of $1 \mu \mathrm{l} / \mathrm{min}$, and then the needle was left in place for 1 additional minute. Animals were injected with either $\beta$-cyclodextrin encapsulated estradiol (Sigma) dissolved in sterile saline (corresponding to $2.3 \mu \mathrm{g}$ of free estradiol) or vehicle ( $\beta$-cyclodextrin in saline) and either STAT3 inhibitor peptide (Calbiochem, 67 pmol) dissolved in sterile saline or saline.

Histology and Fluoro-Jade labeling. Seven days after global ischemia, rats were transcardially perfused using $0.9 \%$ saline with heparin followed by ice-cold $4 \%$ paraformaldehyde (w/v) in PBS. Brains were removed, placed in formalin at $4^{\circ} \mathrm{C}$ overnight, fixed in $30 \%$ sucrose in PBS at $4^{\circ} \mathrm{C}$ for $48 \mathrm{~h}$, and then frozen at $-80^{\circ} \mathrm{C}$. Coronal sections $(20 \mu \mathrm{m})$ were cut at the level of dorsal hippocampus (3.3-4.0 $\mathrm{mm}$ posterior from bregma) with a cryotome, and four sections per animal at $140 \mu \mathrm{m}$ intervals were mounted and stained with toluidine blue or Fluoro-Jade. The processing of brain sections for Fluoro-Jade labeling involves potassium permanganate, which quenches all fluorescence, including green fluorescent protein (GFP). Thus, eGFP does not interfere with the Fluoro-Jade signal (Liu et al., 2004). Viable neurons per $250 \mu \mathrm{m}$ length of medial, middle, and lateral sectors of the CA1 subfield of the left or right hippocampus were counted in four sections per animal under a light microscope at $40 \times$ magnification at $7 \mathrm{~d}$ after ischemia. Counts of surviving neurons were averaged to provide a single value (number of neurons $/ 250 \mu \mathrm{m}$ length) for each animal. All cell counts were performed by an investigator who was blind to the animal's treatment.

Western blotting. Western blot analysis was performed as described previously (Jover-Mengual et al., 2007). In brief, brains were removed from experimental and control animals at various times after ischemia or sham surgery, hippocampi were rapidly dissected, and transverse slices of dorsal hippocampus $(1 \mathrm{~mm})$ were cut with a Mcllwain tissue chopper. The CA1 subfields were microdissected and placed in ice-cold PBS supplemented with a $1 \%(\mathrm{v} / \mathrm{v})$ mixture of protease and phosphatase inhibitors (Sigma). Tissue was homogenized in homogenization buffer $(20 \mathrm{~mm}$ HEPES, $1 \mathrm{~mm} \mathrm{MgCl}_{2}$, $2 \mathrm{~mm}$ EGTA, $1 \mathrm{~mm}$ dithiothreitol, and $320 \mathrm{~mm}$ sucrose, supplemented with a $1 \%$ mixture of protease and phosphatase inhibitors). The lysate was centrifuged at $1000 \mathrm{~g}\left(10 \mathrm{~min}\right.$ at $\left.4^{\circ} \mathrm{C}\right)$ to separate the cytoplasmic (supernatant) and nuclear (pellet) fractions. Protein concentration was determined by BCA protein assay kit (Pierce). Aliquots of protein $(30-40 \mu \mathrm{g})$ were run on SDS/PAGE gels $(4-20 \%$, $\mathrm{w} / \mathrm{v}$ ), transferred to a nitrocellulose membrane, and probed with antibody [anti-STAT3, 1:1000 (Cell Signaling Technology); anti-phosphoSTAT3 (Tyr 705), 1:1000 (Cell Signaling Technology); anti-Bcl-xL 1:1000 (Cell Signaling Technology); anti-Mn-SOD 1:1000 (Cell Signaling Technology); anti-survivin 1:1000 (Cell Signaling Technology); anti$\alpha$-tubulin 1:10,000 (Sigma); anti- $\beta$-actin 1:10,000 (Sigma); anti-histone H3 1:10,000 (Cell Signaling Technology)]. Band density values were normalized to $\beta$-actin (cytoplasmic samples) or histone H3 (nuclear samples). Phospho-STAT3 only was normalized to total STAT3.

Quantitative reverse transcription-PCR. Hippocampi were rapidly dissected and the CA1 subfields microdissected (see above). Tissue was placed in ice-cold PBS, and RNA was extracted using TRIzol reagent 
(Invitrogen). RNA concentration was measured by means of a NanoDrop 2000 (Thermo Scientific). Aliquots of RNA $(1 \mu \mathrm{g})$ were reverse-transcribed to cDNA with SuperScript III Reverse Transcriptase (Invitrogen). Realtime PCR quantification of Bcl-xL, Mn-SOD, and survivin mRNA level was performed in triplicate using gene-specific primers and SYBR green (Applied Biosystems). Oligonucleotide primers were designed using Primer3 (http://frodo.wi.mit.edu/). As an internal control for normalization, PCRs were performed concurrently with the amplification of the reference gene $\beta$-actin. The relative change in the mRNA expression of the mRNAs studied following global ischemia was determined by the equation: Fold change $=2^{-\Delta \mathrm{Ct}}, \Delta \mathrm{Ct}=(\mathrm{Ct}$ target $-\mathrm{Ct} \beta$-actin) (Livak and Schmittgen, 2001).The $\mathrm{Ct}$ value is the cycle number at which the fluorescence signal crosses a threshold.

shRNAs. STAT3, survivin, and nontargeting (NT) shRNA sequences were engineered in the pcDNATM 6.2-GW/EmGFP shRNA expression vector (Invitrogen): STAT3 shRNA-1 (5' TAG TGA AGA AGT TCA CGT TCT-3'); STAT3 shRNA-2 $\left(5^{\prime}\right.$-TTC ACA AGG TCG ATG ATA TTG-3'); survivin shRNA-1 (5'AAA TCA GGC TCA TTC TCG GTA-3'); survivin shRNA-2 (5' -TGC AGG AGC AAT CCT CCA GGA-3'); and NT shRNA, a silencer resistant shRNA sequence that does not target any known eukaryotic gene (5'-AAA TGT ACT GCG CGT GGA GAC-3'). The efficacy of STAT3 and survivin shRNA was evaluated by Western blot $7 \mathrm{~d}$ after transduction of primary cultures of hippocampal neurons prepared from embryonic day 18 Sprague Dawley rat brains, which express endogenous STAT3 and survivin.

Lentiviral vectors. For RNAi-mediated silencing of STAT3 and survivin in neurons of intact animals, we cloned shRNA in the pcDNATM 6.2-GW/EmGFP expression vector into selfinactivating lentiviral pRRLsin.cPPT.CMV.eGFP.Wpre (Miyawaki et al., 2009; Noh et al., 2012) to generate STAT3, survivin, and NT shRNA transfer constructs. High-titer vesicular stomatitis virus-pseudotyped lentiviral stocks were produced in HEK293T cells (Miyawaki et al., 2009; Noh et al., 2012). In brief, cells were transfected with pRRL.PPT.hCMV.GFP.shRNA. Wpre transfer construct, pMDLg/pRRE, and pRSV-REV packaging constructs, and the envelope protein construct pMD2.G by means of calcium phosphate. To determine viral titers, we transduced N2A cells with serial dilutions of concentrated lentivirus and evaluated GFP fluorescence by flow cytometry at $48 \mathrm{~h}$, after concentration by ultracentrifugation, as described previously (Miyawaki et al., 2009). Titers were $1 \times 10^{8}$ (STAT3 and survivin shRNA) and $1.8 \times 10^{8}$ (NT shRNA) transducing units per milliliter after 200 -fold concentration of vector supernatant.

RNAi-mediated STAT3 and survivin silencing. For in vivo experiments, STAT3, survivin, or NT shRNA was delivered into the hippocampus by stereotaxic injection $14 \mathrm{~d}$ before global ischemia or sham surgery as described previously (Noh et al., 2012). In brief, rats were placed in a stereotaxic frame and anesthetized with isoflurane (see above). Concentrated viral solution $(4.0 \mu \mathrm{l})$ was injected into the right (NT shRNA) and left (STAT3 or survivin shRNA) hippocampus ( $3.0 \mathrm{~mm}$ posterior and 2.0 $0.001 ;{ }^{* *} p<0.01 ;{ }^{*} p<0.05$.
B
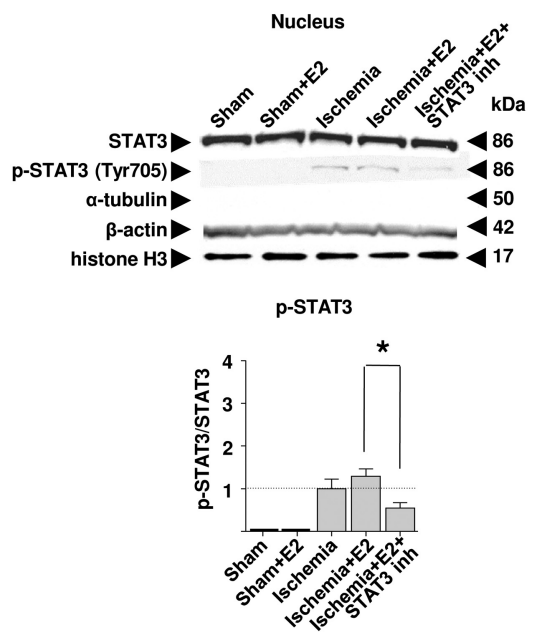

D
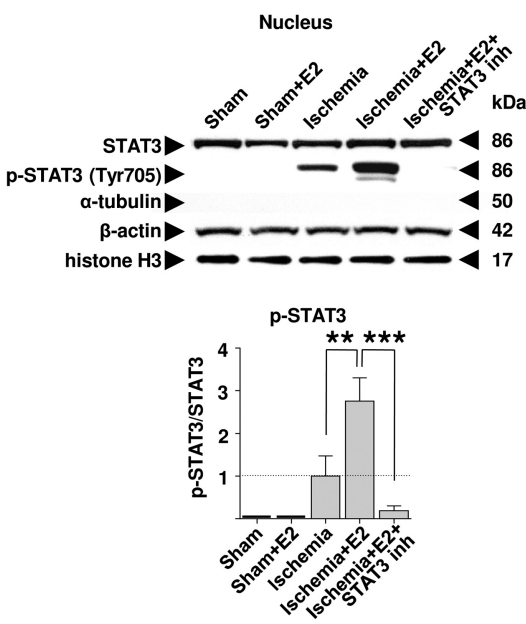

Figure 2. Estradiol elevates phosphorylation of STAT3 in postischemic CA1. A, Top, Representative Westerns showing STAT3 and p-Tyr705-STAT3 in the cytoplasm of CA1 at $3 \mathrm{~h}$ after global ischemia. Bottom, Summary data. Estradiol (E2) did not detectably alter p-Tyr705-STAT3 in sham-operated animals. In contrast, at $3 \mathrm{~h}$ after ischemia, estradiol markedly increased p-Tyr705-STAT3 in the cytoplasm versus that of vehicle-treated ischemic animals (2.28-fold increase vs ischemia, vehicle-infused; $n=5$ per group).

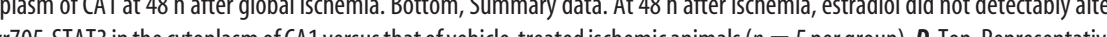
Westerns showing STAT3 and p-Tyr705-STAT3 in the nucleus of CA1 at $48 \mathrm{~h}$ after global ischemia. Bottom, Summary data. At $48 \mathrm{~h}$ after ischemia, estradiol markedly increased p-Tyr705-STAT3 in the nucleus versus that of vehicle-treated ischemic animals (2.75fold increase vs ischemia, vehicle-infused; $n=5$ per group). ANOVA followed by Tukey. Data represent mean \pm SEM; ${ }^{* * *} p<$

$\mathrm{mm}$ lateral to bregma, $4.0 \mathrm{~mm}$ below the skull surface) using a 34 gauge

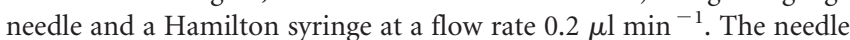
was left in place for an additional $5 \mathrm{~min}$ and then gently withdrawn. We subjected rats to global ischemia or sham surgery $14 \mathrm{~d}$ later and killed them for histology experiments $7 \mathrm{~d}$ after ischemia. We assessed GFP fluorescence in brain sections at the level of the dorsal hippocampus at that time, $21 \mathrm{~d}$ after shRNA injection. Sections were viewed and images were acquired through a Zeiss DUO V2 laser scanning confocal fluorescence microscope. GFP-positive cells were prominent in brain sections ranging from $0.30 \mathrm{~mm}$ rostral to $+0.30 \mathrm{~mm}$ caudal to the injection site.

Chromatin immunoprecipitation assay. The CA1 subfields were microdissected $48 \mathrm{~h}$ after reperfusion and immersed in $1 \%$ formaldehyde $(30$ min at room temperature) to cross-link transcription factors to DNA as described previously (Calderone et al., 2003). The cross-linking reaction 
A

CA1, 7d

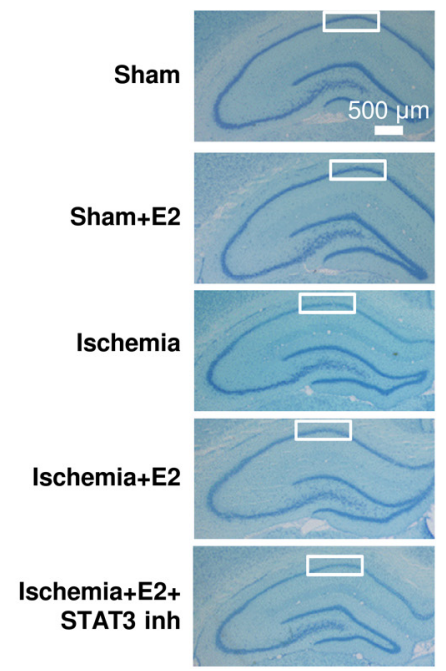

B

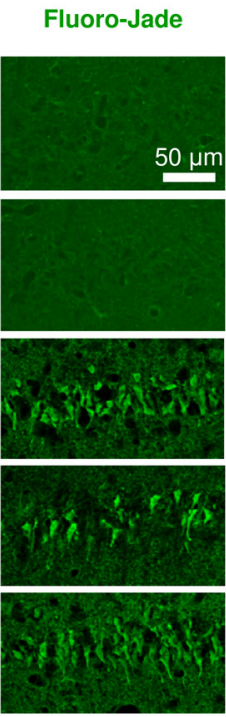

C CA1, 7d
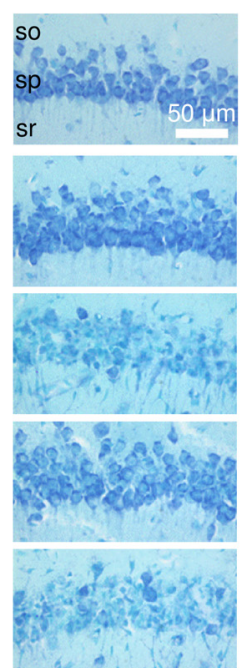

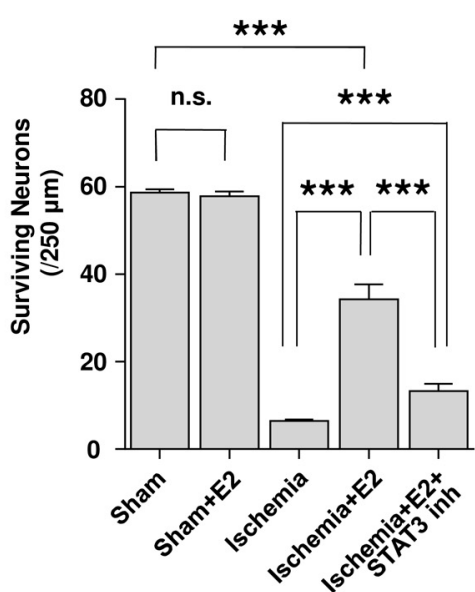

Figure 3. STAT3 peptide inhibitor blocks estradiol neuroprotection. $\boldsymbol{A}, \boldsymbol{B}$, Representative images of toluidine blue $(\boldsymbol{A})$ and Fluoro-Jade staining $(\boldsymbol{B})$ of CA1 pyramidal neurons from rats injected intracerebroventricularly with estradiol (E2) $(2.3 \mu \mathrm{g})$ or vehicle in the presence of STAT3 peptide inhibitor (67 pmol) or vehicle, at $7 \mathrm{~d}$ after sham or global ischemia surgery. Scale bars: low magnification, $500 \mu \mathrm{m}$; higher magnification, $50 \mu \mathrm{m}$. so, Stratum oriens; $5 p$, stratum pyramidale; sr, stratum radiatum. C, Quantification of surviving (A1 pyramidal neurons ( $n=5$ per group) as assessed by toluidine blue staining. Acute estradiol administration partially rescued global ischemia-induced neuronal death and this neuroprotective effect was blocked by administration of STAT3 peptide inhibitor. ANOVA followed by Tukey. Data represent mean \pm SEM; ${ }^{* *} p<0.001$. n.s., Not significant.

was stopped by addition of glycine (final concentration $0.125 \mathrm{M}$ ). The samples were lysed and sonicated to afford chromosomal DNA in the range of $300 \mathrm{bp}$. Aliquots of chromatin were diluted with chromatin immunoprecipitation (ChIP) dilution buffer (167 mM NaCl, $16.7 \mathrm{~mm}$ Tris-HCl, 1.2 mm EDTA, $0.01 \%$ SDS, $1.1 \%$ Triton X-100) to a final volume of $1 \mathrm{ml}$, and an aliquot of pre-immunoprecipitated chromatin ("input," $80 \mu \mathrm{l}$ ) was saved. Samples of chromatin were precleared with Dynabeads M-280 sheep anti-rabbit IgG (Invitrogen) and immunoprecipitated with antibody (10 $\mu \mathrm{g}$ of anti-STAT3). Immunocomplexes were collected on the Dynabeads and eluted with elution buffer (50 mм Tris, 10 mm EDTA, 1\% SDS). After elution, samples of DNA were treated with proteinase K (Qiagen) and purified by means of a PCR purification kit (Qiagen). Survivin, Bcl-xL, and Mn-SOD promoter abundance was quantified by real-time PCR using gene-specific primers and SYBR green. The real-time PCR ChIP data were analyzed as were the mRNA data, except that ChIP data were normalized to input rather than to $\beta$-actin.

Statistical analysis. All results are expressed as mean \pm SEM. Data analysis was performed using GraphPad Prism 6.00. Statistical comparisons among groups were conducted using one-way ANOVA with Tukey's post hoc for multiple comparisons (Figs. 1-4, 6-8) or Student's unpaired, two-tailed $t$ test (Fig. 5). Statistical significance was defined as $p<0.05$.

\section{Results}

\section{Ischemia promotes phosphorylation and nuclear} translocation of STAT3

We first examined the impact of global ischemia on STAT3 phosphorylation in the selectively vulnerable hippocampal CA1. Toward this end, ovariectomized female rats were subjected to a clinicallyrelevant model of global ischemia or sham operation, and STAT3 abundance and phosphorylation status were assessed in the cytoplasmic and nuclear fractions of CA1 at times after ischemia. In sham-operated (control) animals, STAT3 was abundant, but phosphorylation of STAT3 at Tyr705 (p-STAT3) was undetectable in either the cytoplasmic (Fig. $1 A$ ) or nuclear (Fig. $1 B$ ) fractions, as assessed by Western blot analysis. Ischemia induced a striking, but transient, increase in phosphorylation of STAT3 at Tyr705, with little or no change in total STAT3 abundance. In the cytoplasm, phosphorylation of STAT3 at Tyr705 was maximal by $3 \mathrm{~h}$, after which it declined to near control values (Fig. $1 A$ ). In the nucleus, phosphorylation of STAT3 was maximal by $24 \mathrm{~h}$ (Fig. 1B). These findings indicate that phosphorylation of STAT3 at Tyr705 is increased in both the cytoplasm and nucleus in response to ischemia, with a delay in the nucleus, where it acts on target genes. These findings are consistent with the possibility that ischemia induces phosphorylation of STAT3 at Tyr705 in the cytoplasm, followed by nuclear translocation of p-STAT3.

\section{Estradiol enhances and STAT3 peptide inhibitor blunts} phosphorylation of STAT3 in the nucleus of insulted neurons We next examined the impact of estradiol on STAT3 phosphorylation in postischemic CA1 neurons. Toward this end, rats were subjected to global ischemia or sham operation, and a single, acute injection of $17 \beta$-estradiol or vehicle was administered immediately after ischemia in the presence or absence of a highly specific peptide inhibitor of STAT3 (Turkson et al., 2001). Estradiol did not detectably alter the abundance or phosphorylation status of STAT3 at Tyr 705 in the cytoplasm (Fig. 2A) or nucleus (Fig. $2 B$ ) of sham-operated animals. By $3 \mathrm{~h}$ after ischemia, estradiol markedly increased the phosphorylation status of STAT3 at Tyr705 in the cytoplasm (Fig. 2A), but not the nucleus (Fig. 2B), relative to that of animals subjected to ischemia alone. By $48 \mathrm{~h}$ after ischemia, the phosphorylation status of STAT3 at Tyr705 was slightly, but not significantly, increased in the cytoplasm (Fig. $2 C$ ), but was markedly increased in the nucleus (Fig. 2D) of CA1 cells. The STAT3 inhibitor peptide reversed estradiol-induced STAT3 phosphorylation in the cytoplasm and the nucleus at 3 and $48 \mathrm{~h}$ after ischemia, the only time points examined (Fig. $2 A-D)$. The finding that estradiol-induced phosphorylation of STAT3 in the cytoplasm precedes that in the nucleus by many hours suggests that p-STAT3 is phosphorylated in the cytoplasm and then translocates to the nucleus in postischemic CA1 neurons. The finding that the STAT3 inhibitor peptide markedly 
A

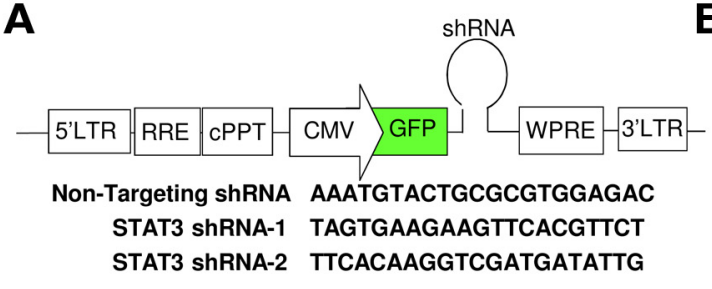

C CA1, 7d

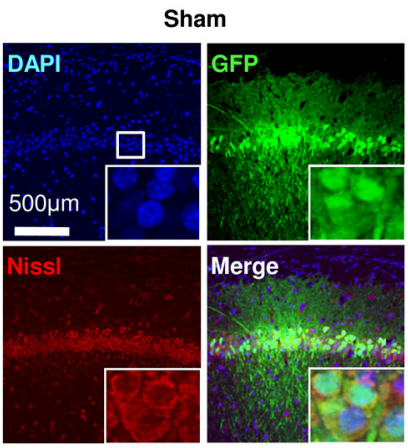

Ischemia

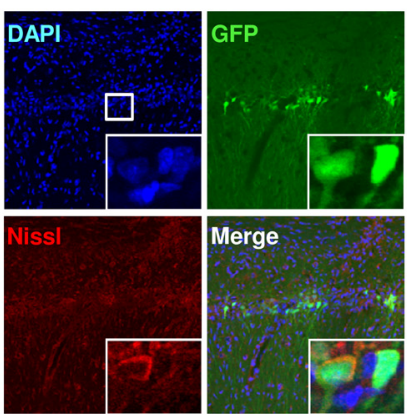

D

CA1, 7d
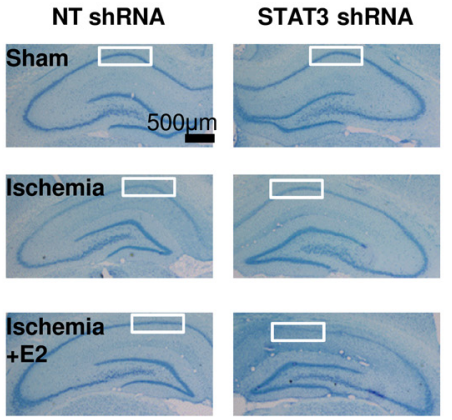

Hippocampal neurons

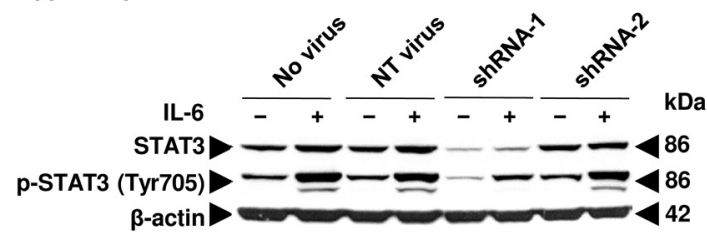

E

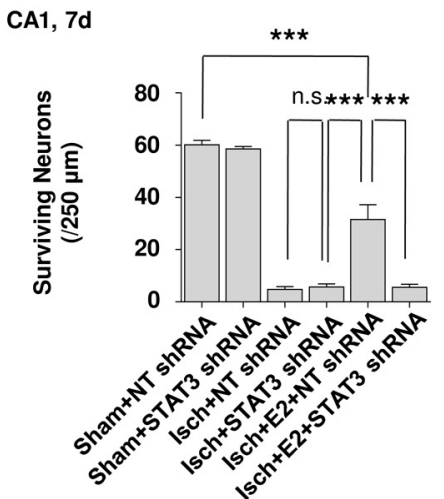

$\mathbf{F}$

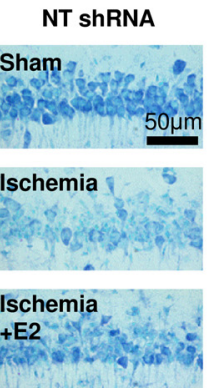

STAT3 ShRNA
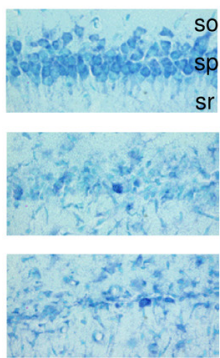

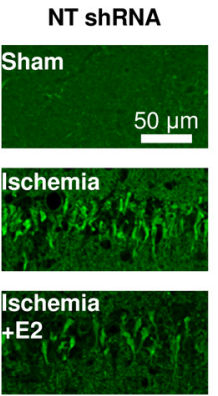

STAT3 shRNA
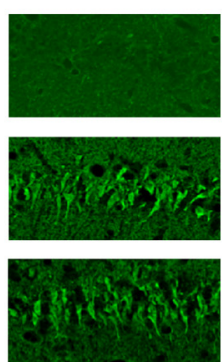

Figure 4. Knockdown of STAT3 blocks estradiol neuroprotection. $A$, Schematic of the shRNA lentiviral transfer vector and shRNA sequences used. $B$, shRNA was transduced into rat hippocampal primary culture neurons for $7 \mathrm{~d}$. Transduction of STAT3 shRNA-1 (but not shRNA-2) decreased endogenous STAT3 expression in neurons by $70-80 \%$. C, Representative images of CA1 treated with STAT3 shRNA-17 d after ischemia. The GFP fluorescence was prominent in neurons, but not in other cell types. After induction of ischemia, GFP fluorescence declined, in parallel with neuronal death. $D$, Representative images of toluidine blue staining of CA1 pyramidal neurons at $7 \mathrm{~d}$ after reperfusion. Scale bars: low magnification, $500 \mu \mathrm{m}$; higher magnification, $50 \mu \mathrm{m}$. 50,5 tratum oriens; $\mathrm{Sp}$, stratum pyramidale; sr, stratum radiatum. $E$, Quantification of surviving pyramidal neurons in $C A 1$ at $7 \mathrm{~d}$ after reperfusion illustrated in $\boldsymbol{D}$ ( $n=5$ per group). Animals subjected to global ischemia, followed by vehicle injection, exhibited pronounced ( $\sim 90 \%$ ) neuronal loss of pyramidal neurons in the right CA1 (expressing NT shRNA) and left CA1 (expressing STAT3 shRNA) compared with sham-operated controls $(p<0.001)$. Animals subjected to global ischemia followed by estradiol (E2) had significantly higher numbers of surviving pyramidal neurons $(\sim 50 \%)$ in the right CA1-expressing NT shRNA than in the left CA1-expressing STAT3 shRNA. $\boldsymbol{F}$, Representative images of Fluoro-Jade staining of CA1 degenerating pyramidal neurons at $7 \mathrm{~d}$ after reperfusion. Scale bar, $50 \mu \mathrm{m}$. ANOVA followed by Tukey. Data represent mean \pm SEM; ${ }^{* * *} p<0.001$. n.s., Not significant.

inhibited both ischemia- and estradiol-induced phosphorylation of STAT3 is consistent with the notion that it directly binds STAT3 and prevents STAT3 phosphorylation at Tyr705 (Turkson et al., 2001).

\section{STAT3 inhibitor peptide blocks estradiol neuroprotection}

The results thus far show that estradiol stimulates phosphorylation of STAT3 but do not address the issue of whether STAT3 is critical to estradiol neuroprotection in global ischemia. STAT3 is implicated in estradiol neuroprotection in older female rats subjected to global ischemia (De Butte-Smith et al., 2012) and other models of neuronal death (Dziennis et al., 2007). To address this issue, we undertook two experimental approaches. First, we examined the effect of the cell-permeable STAT3 inhibitor peptide on estradiol neuroprotection in an in vivo model of global ischemia. Toward this end, we subjected animals to global ischemia or sham operation and administered a single, acute injection of $17 \beta$-estradiol or vehicle in the presence or absence of STAT3 inhibitor peptide immediately after ischemia. Surviving CA1 pyramidal neurons were counted $7 \mathrm{~d}$ after ischemia. In animals treated with vehicle, global ischemia induced pronounced neuronal death of CA1 pyramidal neurons relative to vehicleinjected, sham-operated animals, as assessed by toluidine blue staining (Fig. $3 A, C$ ) or Fluoro-Jade labeling (Fig. 3B). Estradiol afforded robust protection of postischemic CA1 neurons (Fig. 3C). STAT3 inhibitor peptide markedly attenuated estradiol neuroprotection in animals subjected to global ischemia (Fig. 3A-C), but had little or no effect on neuronal survival in sham-operated animals (data not shown).

\section{Knockdown of STAT3 blocks estradiol neuroprotection}

As a parallel and complementary approach, we took advantage of RNAi-mediated gene silencing and the lentivirus expression system for in vivo delivery of STAT3 shRNA into the CA1. To evaluate the efficacy of STAT3 shRNA, we expressed two different STAT3 shRNA constructs in primary cultures of hippocampal 
neurons (Fig. 4A). Transduction of STAT3 shRNA-1 was more effective than shRNA-2 and decreased endogenous STAT3 expression in neurons by 70 to $80 \%$ (Fig. $4 B$ ). We used shRNA-1 for all in vivo experiments. To evaluate the efficacy of lentivirus expression in vivo, we first monitored GFP expression in the right and left CA1 in brain sections ranging from $0.30 \mathrm{~mm}$ rostral to $0.30 \mathrm{~mm}$ caudal to the injection site (Fig. 4C). GFP fluorescence was prominent in the CA1 pyramidal cell layer, which contains $\sim 95 \%$ pyramidal neurons.

We next examined the impact of STAT3 shRNA on estradiol neuroprotection in an in vivo model of global ischemia. Toward this end, we injected nontargeting (NT) shRNA directly into the right CA1 and STAT3 shRNA-1 directly into the left CA1 of living rats and $14 \mathrm{~d}$ later, subjected rats to global ischemia or sham operation. A single, acute injection of $17 \beta$-estradiol or vehicle was administered immediately after reperfusion. Animals subjected to global ischemia, followed by vehicle injection, exhibited pronounced ( $\sim 90 \%$ ) neuronal loss of pyramidal neurons in the right CA1 (expressing NT shRNA) and left CA1 (expressing STAT3 shRNA), relative to that of sham-operated controls as assessed by toluidine blue staining (Fig. 4D,E). Animals subjected to global ischemia followed by estradiol had significantly higher numbers of surviving pyramidal neurons ( $~ 50 \%)$ in the CA1-expressing NT shRNA versus the CA1-expressing STAT3 shRNA (Figure $4 D, E$ ). Similarly, Fluoro-Jade labeling of degenerating neurons showed reduced cell death in the right CA1 (NT shRNA) compared with the left CA1 (STAT3 shRNA) (Fig. 4F). These findings indicate that the neuroprotective actions of estradiol were abolished by knockdown of STAT3 in the CA1 pyramidal cell layer.

\section{STAT3 promotes active transcription of survivin in hippocampal neurons}

The results thus far indicate that ischemia promotes and estradiol enhances STAT3 phosphorylation in the nucleus of CA1 pyramidal neurons, but do not address the impact of ischemia on association of STAT3 with its target genes. To address this issue, we used ChIP to examine STAT3 occupancy at the promoters of genes encoding Bcl-xL, Mn-SOD, and survivin, STAT3 targets implicated in neuroprotection, in postischemic CA1. In control CA1, STAT3 occupancy was low but detectable (data not shown). Ischemia induced enrichment of STAT3 at the promoters of Bcl$\mathrm{xL}, \mathrm{Mn}-\mathrm{SOD}$, and survivin in CA1, evident at $48 \mathrm{~h}$ after ischemia, the only time point examined, relative to that of control CA1 (Fig. $5 A$ ). Of the genes examined, survivin exhibited the greatest enrichment. In contrast, ischemia did not detectably alter STAT3 occupancy at sites either $1 \mathrm{~kb}$ or $3 \mathrm{~kb}$ upstream from the survivin promoter or at the promoter of the $\beta$-actin gene, a negative control (Fig. $5 B$ ). These findings demonstrate that ischemia increases the binding of STAT3 to promoters of target genes and document specificity of its interaction with the promoters of target genes.

\section{Ischemia induces mRNA and protein expression of STAT3 targets important to neuronal survival}

To examine the impact of ischemia on Bcl-xL, Mn-SOD, and survivin mRNA expression in CA1, animals were subjected to global ischemia or sham operation, and mRNA was quantified by qRT-PCR at times after ischemia. Whereas ischemia induced a relatively modest increase in $\mathrm{Bcl}-\mathrm{xL}$ and $\mathrm{Mn}$-SOD mRNA expression in CA1, which peaked at $24 \mathrm{~h}$, it induced a striking increase in survivin mRNA in CA1, which was evident at $48 \mathrm{~h}$ and persisted as late as $72 \mathrm{~h}$ after ischemia (Fig. 6A). To examine whether the changes in target gene expression were translated into changes in
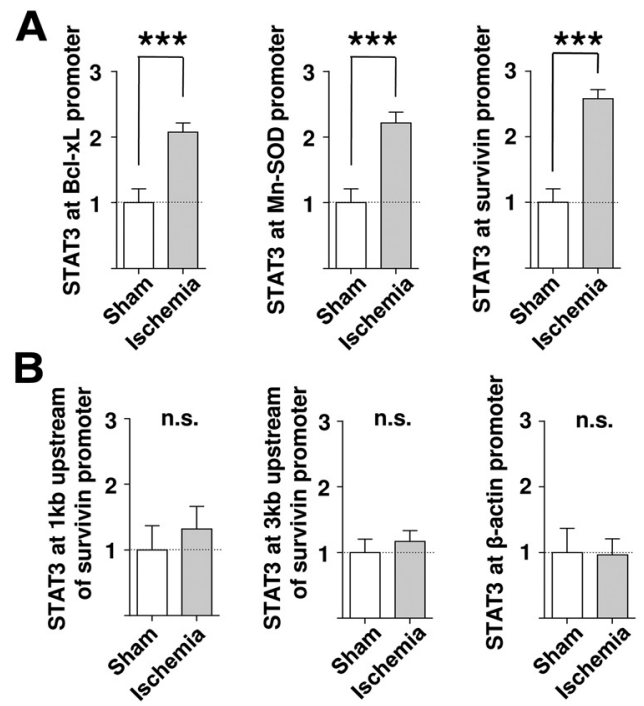

Figure 5. STAT3 is a potential transcriptional regulator of the rat survivin gene. $A$, Ischemiainduced enrichment of STAT3 at the promoters of BCl-xL, Mn-SOD, and survivin in CA1 at $48 \mathrm{~h}$ after ischemia, the only time point examined, relative to that of control CA1 (2.07-, 2.21-, and 2.58 -fold increase, respectively, vs sham; $n=4$ per group). $\boldsymbol{B}$, In contrast, ischemia did not detectably alter STAT3 at sites either $1 \mathrm{~kb}$ or $3 \mathrm{~kb}$ upstream from the survivin promoter or at the promoter of the $\beta$-actin gene ( $n=4$ per group). Student's $t$ test was used. Data represent mean \pm SEM; ${ }^{* * *} p<0.001$. n.S., Not significant.

protein, we assessed $\mathrm{Bcl}-\mathrm{xL}, \mathrm{Mn}-\mathrm{SOD}$, and survivin protein abundance in the cytoplasm and nucleus of CA1 by Western blot analysis at times after ischemia (Fig. 6B,C). Whereas ischemia did not detectably alter $\mathrm{Bcl}-\mathrm{xL}$ or $\mathrm{Mn}-\mathrm{SOD}$ protein abundance in the cytoplasm or nucleus of CA1 at times examined, it induced a marked increase in survivin protein expression in both fractions evident at $48 \mathrm{~h}$ and even more striking at $72 \mathrm{~h}$ after ischemia. Ischemia-induced enhancement of Bcl-xL and Mn-SOD mRNA, but not protein, is consistent with additional regulation of $\mathrm{Bcl}-\mathrm{xL}$ and $\mathrm{Mn}-\mathrm{SOD}$ at the post-transcriptional level. These findings document specificity of STAT3 transcription in postischemic CA1 and are consistent with the possibility that survivin expression plays a role in the fate of postischemic CA1 neurons.

\section{Estradiol further increases mRNA and protein expression of STAT3 target genes in postischemic CA1}

We next examined the impact of estradiol on Bcl-xL, Mn-SOD, and survivin mRNA expression in postischemic CA1 neurons. Toward this end, we subjected animals to global ischemia or sham operation, administered a single, acute injection of estradiol or vehicle immediately after ischemia, and assessed mRNA expression by qRT-PCR at $48 \mathrm{~h}$ after ischemia. Whereas estradiol did not significantly alter Bcl-xL or Mn-SOD mRNA expression, it induced a striking increase in survivin mRNA in CA1 at $48 \mathrm{~h}$ (Fig. 7A). To examine whether changes in target gene expression were translated into changes in protein, we examined the impact of estradiol on survivin protein abundance in CA1 at $48 \mathrm{~h}$ after ischemia by Western blot analysis (Fig. $7 \mathrm{~B}, \mathrm{C}$ ). Estradiol induced a striking increase in survivin protein abundance in the cytoplasm and nucleus of CA1. To determine whether STAT3 is causally related to the ischemia and estradiol-induced increase in survivin protein in CA1, we injected the STAT3 inhibitor peptide or vehicle immediately after ischemia. The STAT3 peptide inhibitor prevented the upregulation of survivin in both cytoplasm and nucleus (Fig. $7 \mathrm{~B}, \mathrm{C}$ ) indicating that STAT3 activation is critical to survivin transcription in insulted hippocampal neurons. 
A

mRNA

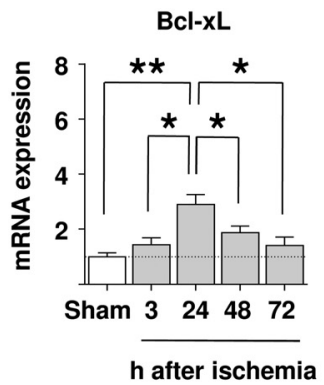

B
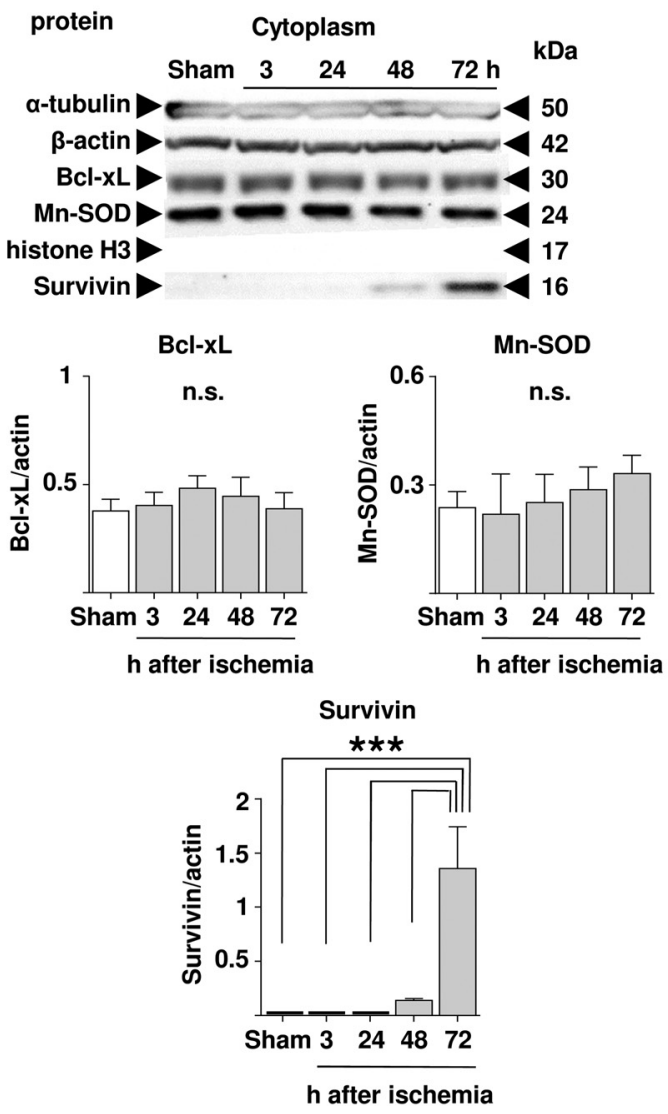

Mn-SOD

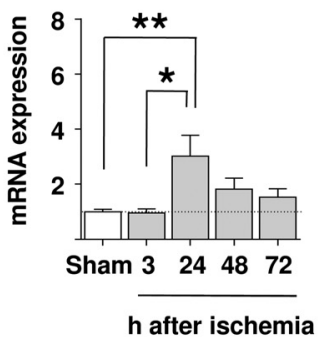

C

C

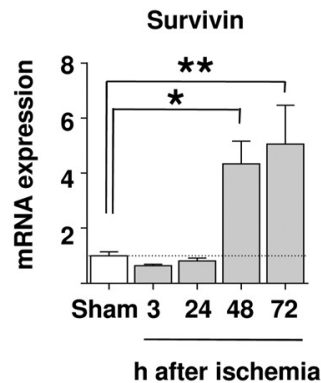

$\mathrm{h}$ after ischemia
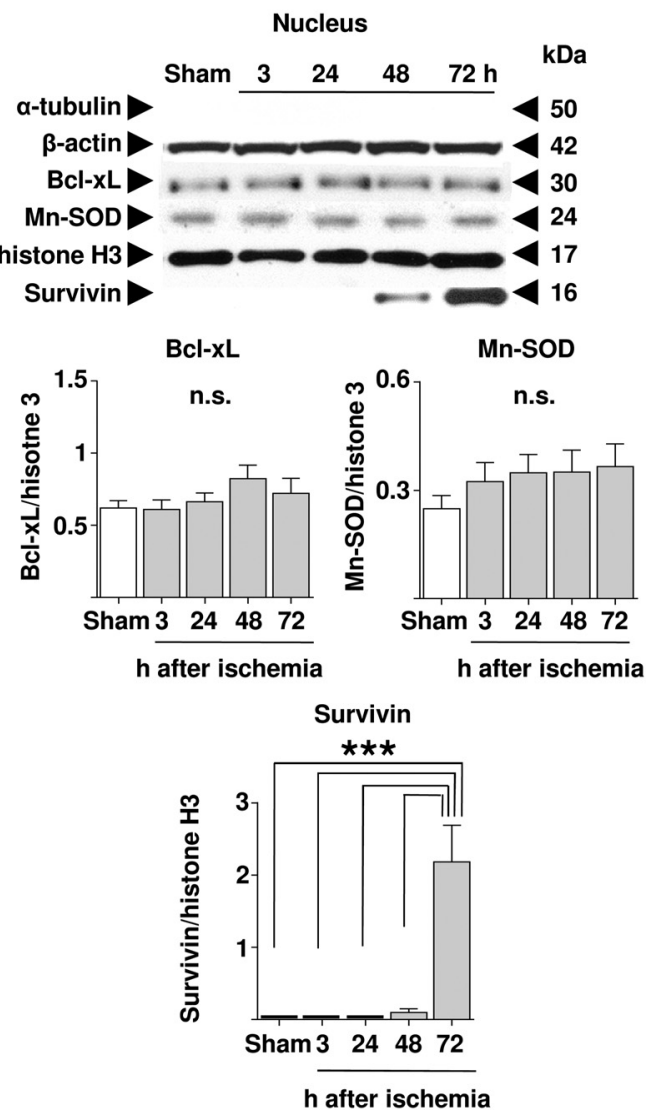

Figure 6. Ischemia induces mRNA and protein expression of STAT3 target genes important to neuronal survival. $A$, Global ischemia induced a marked increase in Bcl-xL, Mn-SOD, and survivin mRNA expression. BCl-xL and Mn-SOD mRNA were maximal at $24 \mathrm{~h}$ (2.91-and 3.01-fold increase, respectively, vs sham; $n=5$ per time point). In contrast, survivin mRNA upregulation was not altered before $48 \mathrm{~h}$, but was striking and maximal at $72 \mathrm{~h}$ after ischemia (4.35-and 5.07-fold increase, respectively, vs sham; $n=5$ per time point). $\boldsymbol{B}$, Top, Representative Westerns showing Bcl-xL, Mn-SOD, and survivin protein in the cytoplasm of CA1 at times after global ischemia. Bottom, Summary data. Survivin was first evident at $48 \mathrm{~h}$ and was dramatically elevated at $72 \mathrm{~h}$ in the cytoplasm of CA1 ( $n=5$ per group). $\boldsymbol{C}$, Top, Representative Westerns showing BCl-xL, Mn-SOD, and survivin in the nucleus of CA1 at times after global ischemia. Bottom, Summary data. Survivin was first evident at $48 \mathrm{~h}$ and was striking at $72 \mathrm{~h}$ after ischemia in the nuclear fraction of CA1 ( $n=5$ per group). ANOVA followed by Tukey. Data represent mean \pm SEM; ${ }^{* * *} p<0.001 ;{ }^{* *} p<0.01 ;{ }^{*} p<0.05$. n.s., Not significant.

Knockdown of survivin blocks estradiol neuroprotection To examine a possible role for survivin in estradiol neuroprotection, we delivered NT shRNA into the right CA1 and survivin shRNA into the left CA1 and $14 \mathrm{~d}$ later, subjected animals to global ischemia or sham operation, followed immediately by a single, acute injection of estradiol or vehicle. To validate the specificity and efficacy of survivin shRNA, we transduced two different survivin shRNA constructs, survivin shRNA-1 or shRNA-2 (Fig. 8A), into primary cultures of hippocampal neurons, which express endogenous survivin. Transduction of either survivin shRNA-1 or shRNA-2 decreased survivin protein abundance in hippocampal neurons by $\sim 90 \%$ (Fig. $8 B$ ). We used shRNA-1 for in vivo experiments. To evaluate the efficacy of lentivirus expres- sion, we monitored GFP fluorescence in the right and left CA1 in brain sections ranging from $0.30 \mathrm{~mm}$ rostral to $0.30 \mathrm{~mm}$ caudal to the injection site. GFP fluorescence was prominent within the CA1 pyramidal cell layer (Fig. $8 C$ ).

We next examined the impact of survivin shRNA on estradiol neuroprotection in an in vivo model of global ischemia. Toward this end, we injected NT shRNA into the right CA1 and survivin shRNA into the left CA1 of living rats and $14 \mathrm{~d}$ later, subjected rats to global ischemia or sham operation. A single, acute injection of $17 \beta$-estradiol or vehicle was administered immediately after reperfusion. Animals subjected to global ischemia followed by vehicle exhibited pronounced ( $~ 90 \%)$ neuronal loss of pyramidal neurons in the right CA1 (expressing NT shRNA) and left 
A

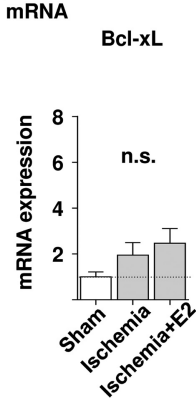

B

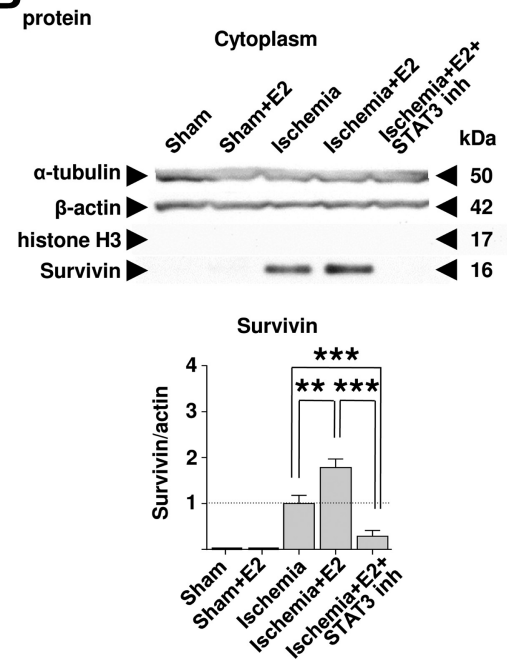

Mn-SOD

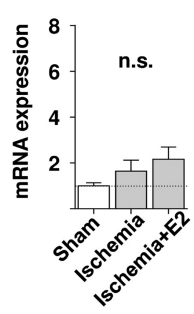

C

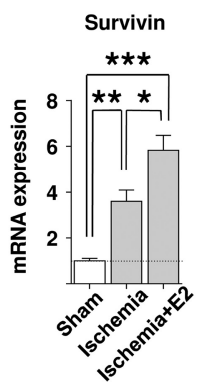

Nucleus
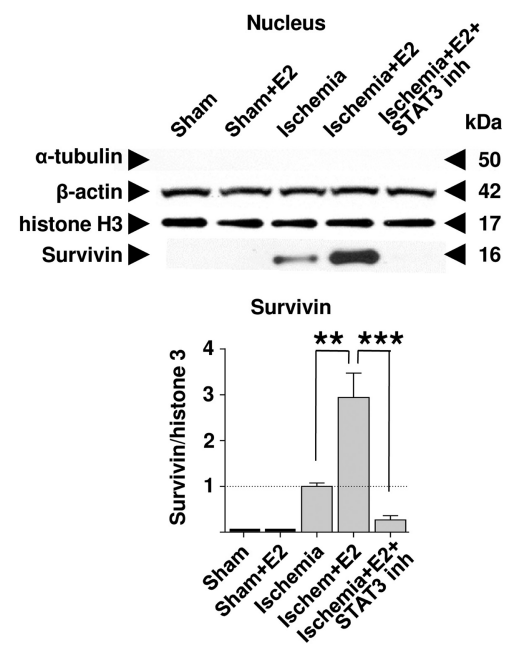

Figure 7. Estradiol further increases mRNA and protein expression of STAT3 target genes in postischemic CA1. $\boldsymbol{A}$, Summary data of mRNA levels of BCl-xL, Mn-SOD, and survivin in CA1 at $48 \mathrm{~h}$ after global ischemia. Estradiol (E2) did not significantly alter BCl-xL or Mn-SOD mRNA expression at $48 \mathrm{~h}$, the only time point examined. In contrast, estradiol induced a striking increase in survivin mRNA expression in CA1 (1.62-fold increase vs vehicle-injected ischemic rats; $n=5$ per group). $\boldsymbol{B}$, Top, Representative Westerns showing survivin in the cytoplasm of CA1 at $48 \mathrm{~h}$ after global ischemia. Bottom, Summary data. Estradiol induced a marked increase in survivin protein expression in the cytoplasm at $48 \mathrm{~h}$ after ischemia (1.78-fold increase vs vehicle-injected ischemic rats; $n=5$ per group). C, Top, Representative Westerns showing survivin in the nucleus of CA1 at $48 \mathrm{~h}$ after global ischemia. Bottom, Summary data. Estradiol induced a marked increase in survivin protein expression in the nucleus at $48 \mathrm{~h}$ after ischemia (2.94-fold increase vs vehicle-injected ischemic rats; $n=5$ per group). STAT3 inhibitor peptide prevented the estradiol-induced increase in survivin abundance in the cytoplasm and nucleus (decrease to 29 and $27 \%$, respectively, vs vehicle-injected ischemic rats). ANOVA followed by Tukey. Data represent the mean \pm SEM; ${ }^{* * *} p<0.001 ;{ }^{* *} p<0.01 ;{ }^{*} p<0.05$. n.S., Not significant.

In animals subjected to ischemia, a single acute injection of estradiol administered after ischemia further enhances activation and nuclear translocation of STAT3 and STAT3-dependent transcription of survivin. Both the ischemia- and estradiolinduced increases in survivin were reversed by the STAT3 inhibitor peptide. Collectively, these findings indicate that ischemia and estradiol act synergistically to promote activation of STAT3 and STAT3-dependent transcription of survivin in insulted CA1 neurons. This is significant in that survivin inhibits caspasedependent and caspase-independent cell death (Eckelman et al., 2006; Gyrd-Hansen and Meier, 2010). Importantly, we show that STAT3 is essential to estradiol neuroprotection, as evidenced by the ability of STAT3 inhibitor peptide and STAT3 shRNA delivered directly into the CA1 of living animals to abolish estradiol neuroprotection. In addition, we identify survivin, a gene target of STAT3, as essential to estradiol neuroprotection, as evidenced by the ability of knockdown of survivin in the CA1 in vivo to abolish estradiol neuroprotection. To our knowledge, this is the first demonstration that STAT3 promotes active transcription of survivin in neurons and that survivin is critical to estradiol neuroprotection.

\section{STAT3 is critical to estradiol neuroprotection}

STAT proteins are a family of transcription factors that play a crucial role in growth and differentiation in a variety of cell types (Horvath, 2000; Bromberg and Darnell, 2000; Reich and Liu, 2006). In the present study we show that ischemia promotes phosphorylation and nuclear translocation of p-STAT3 in CA1, where it CA1 (expressing survivin shRNA), relative to that of shamoperated controls (Fig. 8D-F). Animals subjected to global ischemia followed by estradiol had significantly higher numbers of surviving pyramidal neurons $(\sim 50 \%)$ in the right CA1 (expressing NT shRNA), relative to that of the left CA1 (expressing survivin shRNA; Fig. $8 D-F)$. These findings demonstrate that knockdown of survivin abolishes estradiol neuroprotection and identify survivin as a critical downstream target of STAT3 that is essential for neuroprotection.

\section{Discussion}

In this study we show that a single intracerebral injection of $17 \beta$ estradiol to ovariectomized female rats immediately after an ischemic episode rescues hippocampal CA1 pyramidal neurons destined to die. Ischemia promotes phosphorylation and activation of STAT3 signaling, association of p-STAT3 with promoters of target genes, and STAT3-dependent increases in mRNA and protein expression of prosurvival target genes in the selectively vulnerable hippocampal CA1. Notably, ischemia induces a specific and striking increase in the inhibitor-of-apoptosis protein survivin. is strategically positioned in close proximity to prosurvival target genes such as Bcl-xL, Mn-SOD, and survivin. Consistent with this, ischemia promotes association of STAT3 with the promoters of these target genes and increases mRNA expression. Whereas ischemia induces a relatively modest and transient increase in $\mathrm{Bcl}-\mathrm{xL}$ and Mn-SOD mRNA expression with little or no change in protein, it induces a striking increase in survivin mRNA and protein. Interestingly, focal ischemia also promotes phosphorylation and nuclear translocation of STAT3 in the cerebral cortex (Suzuki et al., 2001; Wen et al., 2001; Satriotomo et al., 2006; Dziennis et al., 2007; for review, see Jung et al., 2009). Moreover, STAT3 is critical to estradiol neuroprotection in the cerebral cortex following focal ischemia (Dziennis et al., 2007). The finding of commonalities between focal and global ischemia, namely activation and nuclear translocation of STAT3 in postischemic neurons and a role for STAT3 in estradiol neuroprotection, is unexpected in that the paradigms target different populations of neurons and induce cell death via different mechanisms (Ofengeim et al., 2011). 
A
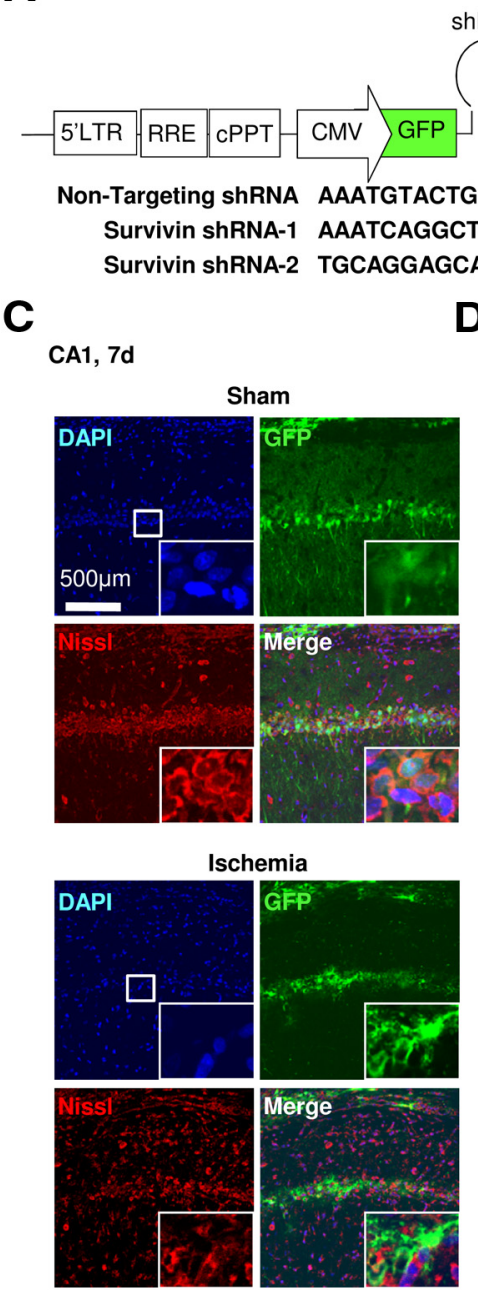

B

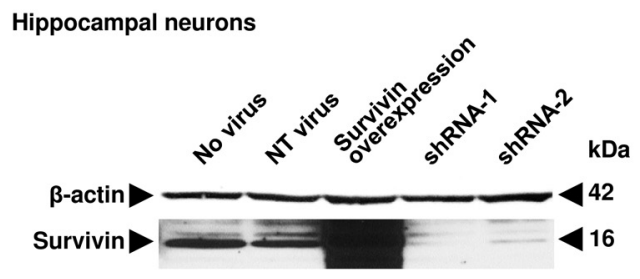

E

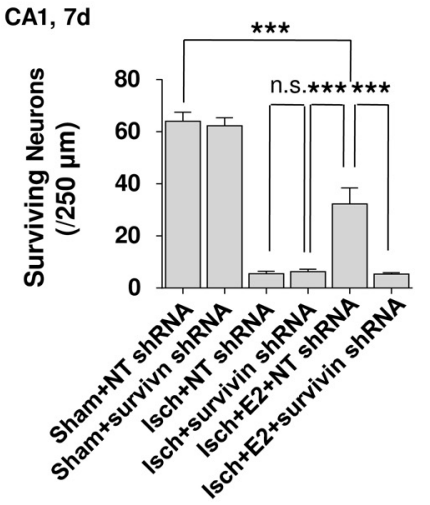

$\mathbf{F}$
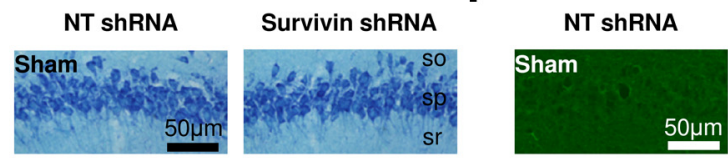

Survivin ShRNA

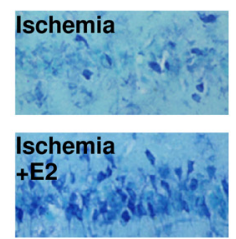

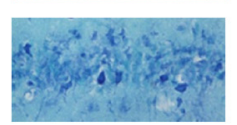

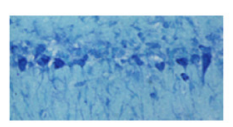

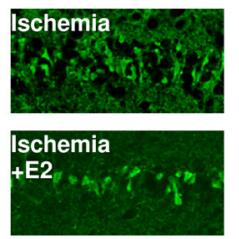
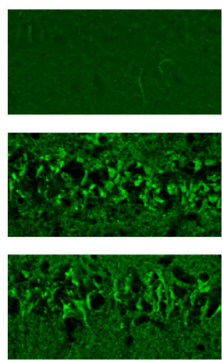

Figure 8. Knockdown of survivin blocks estradiol neuroprotection. $\boldsymbol{A}$, Schematic of the shRNA lentiviral transfer vector and shRNA sequences used. $\boldsymbol{B}$, shRNA was transduced into rat hippocampal primary culture neurons for $7 \mathrm{~d}$. Transduction of either survivin shRNA-1 or shRNA-2 decreased endogenous STAT3 expression in neurons by $90 \%$. C, Representative images of CA1 treated with survivin shRNA $7 \mathrm{~d}$ after ischemia. The GFP fluorescence was prominent in neurons. After induction of ischemia, GFP fluorescence declined, in parallel with loss of neurons. D, Representative images of toluidine blue staining of CA1 pyramidal neurons at $7 \mathrm{~d}$ after reperfusion. Scale bars: low magnification, $500 \mu \mathrm{m}$; high magnification, $50 \mu \mathrm{m}$. so, Stratum oriens; sp, stratum pyramidale; sr, stratum radiatum. $E$, Quantification of surviving pyramidal neurons in CA1 at $7 \mathrm{~d}$ after reperfusion ( $n=5$ per group). Animals subjected to global ischemia, followed by vehicle injection, exhibited pronounced ( $\sim 90 \%$ ) neuronal loss of pyramidal neurons in the right CA1 (expressing NT shRNA) and left CA1 (expressing survivin shRNA) compared with sham-operated controls. Animals subjected to global ischemia followed by estradiol (E2) had significantly higher numbers of surviving pyramidal neurons ( 50\%) in the right CA1-expressing NT shRNA than ischemic rats treated estradiol in the left CA1-expressing survivin shRNA. $F$, Representative images of Fluoro-Jade staining of CA1 pyramidal neurons at $7 \mathrm{~d}$ after reperfusion. Scale bar, $50 \mu \mathrm{m}$. ANOVA followed by Tukey. Data represent mean \pm SEM; ${ }^{* * *} p<0.001$. n.S., Not significant.

Of the three STAT3 targets tested (survivin, Mn-SOD, and Bcl-xL), STAT3 preferentially activated survivin. Although ischemia increased binding to the Mn-SOD and Bcl-xL promoters, neither ischemia nor estradiol detectably altered Mn-SOD or $\mathrm{Bcl}-\mathrm{xL}$ protein expression. In contrast, STAT3-dependent transcription of Mn-SOD is implicated in estradiol neuroprotection in a model of focal ischemia. Mn-SOD is an antioxidant enzyme that scavenges superoxide radicals to protect against oxidative stress (Chen et al., 2011). Inhibition of STAT3 reduces Mn-SOD expression, increases superoxide anions, and enhances focal ischemia-induced neuronal death (Jung et al., 2009). Bcl-xL is a member of the Bcl-2 family of proteins, which serve as central regulators of intrinsic programmed cell death (Youle and Strasser, 2008; Hardwick and Youle, 2009; Chipuk et al., 2010). Whereas full-length $\mathrm{Bcl}-\mathrm{xL}$ is anti-apoptotic, injurious stimuli such as global ischemia promote proteolytic cleavage of Bcl-xL to generate its pro-apoptotic counterpart, truncated $\mathrm{Bcl}-\mathrm{xL}$ or $\Delta \mathrm{N}$ Bcl-xL (Jonas et al., 2005; Bonanni et al., 2006; Miyawaki et al.,
2008). Thus, although activation of STAT3 may afford neuroprotection in models of both focal and global ischemia, the downstream mechanisms likely differ in the two paradigms.

Survivin is a STAT3 gene target critical to estradiol neuroprotection in global ischemia

To our knowledge, the present study is the first to demonstrate that ischemia (or any injurious stimulus) induces STAT3dependent upregulation of the inhibitor-of-apoptosis protein survivin and that survivin is causally related to estradiol neuroprotection in any model of ischemia. Our finding that global ischemia promotes upregulation of survivin in CA1 differs from findings of others who report that global ischemia induces downregulation of survivin (Zhang et al., 2008; Scott et al., 2013). Our finding that a single, acute injection of estradiol administered after ischemia promotes expression of survivin in postischemic CA1 is consistent with findings of others that estradiol administered chronically to ovariectomized female rats before induction 
of global ischemia promotes survivin expression in insulted CA1 neurons (Zhang et al., 2008; Scott et al., 2013). Whereas the increase in survivin induced by acute estradiol is STAT3 dependent, the increase in survivin induced by long-term administration of estradiol before the ischemic event is dependent on $\mathrm{Wnt} / \beta$ catenin signaling (Zhang et al., 2008; Scott et al., 2013). It is of interest that two such different signaling pathways can regulate survivin gene expression in insulted CA1 neurons. Whether these pathways act in parallel or are mutually exclusive remains to be determined. In the present study we focused on the neuroprotective effect of estradiol. However, the STAT3-survivin pathway may represent a common downstream mechanism that is critical to the function of other neuroprotective agents. Several growth factors, hormones, and cytokines activate STAT3 and have neuroprotective properties, including leptin, IL-6, granulocyte colony-stimulating factor, and insulin-like growth factor 1 (Dziennis and Alkayed, 2008). However, a potential role for the downstream target survivin has yet to be investigated for these agents.

\section{Estradiol promotes activation of prosurvival pathways}

Findings in the present study show that ischemia promotes activation and nuclear translocation of STAT3 in insulted CA1 neurons, even in the absence of estradiol, and that STAT3 drives transcription of the prosurvival protein survivin. STAT3dependent transcription of survivin in postischemic CA1 may represent a failed attempt to protect selectively vulnerable neurons in the face of global ischemia. In contrast, in animals treated with estradiol, ischemia induces a stronger activation of STAT3 as indicated by the increased levels of p-STAT3 in the nucleus. Our data support a model whereby global ischemia activates both prodeath and prosurvival pathways, with the balance falling in favor of cell death. A single injection of estradiol after the ischemic episode may increase STAT3 and other prosurvival signaling pathways such as ERK/CREB (Jover-Mengual et al., 2007) and PI3K/Akt (Jover-Mengual et al., 2010) above a critical threshold and thereby tip the balance in favor of cell survival. Importantly, it has recently been shown that intracerebroventricular administration of estradiol as late as $6 \mathrm{~h}$ after global ischemia affords significant neuroprotection in hippocampal CA1 (Canal Castro et al., 2012). Thus, administration of estradiol after the ischemic episode may represent a therapeutically relevant mode of neuroprotection in an in vivo model of global ischemia.

In summary, we show that acute administration of estradiol immediately following global ischemia affords neuroprotection that is dependent on activation of the transcription factor STAT3 and its downstream target survivin. Ischemic insults promote STAT3 phosphorylation and activation and STAT3-dependent transcription of survivin in neurons destined to die. Estradiol further enhances STAT3 signaling and STAT3-dependent transcription of survivin, culminating in a striking and long-lasting increase in survivin expression in the hippocampal CA1, which in turn promotes survival of selectively vulnerable CA1 pyramidal neurons. Notably, activation of STAT3 and STAT3-dependent expression of survivin are essential to estradiol neuroprotection. Our study reveals a previously unappreciated role for STAT3 signaling and transcription of its target survivin in the neuroprotection afforded by a single, acute injection of estradiol administered after the ischemic event in an in vivo model of global ischemia. Given the critical role of STAT3 and survivin in neuroprotection, these may be relevant therapeutic targets for the treatment of neurodegeneration and cognitive dysfunction associated with global ischemia.

\section{References}

Altieri DC (2008) New wirings in the survivin networks. Oncogene 27: 6276-6284. CrossRef Medline

Baratchi S, Kanwar RK, Kanwar JR (2010) Survivin: a target from brain cancer to neurodegenerative disease. Crit Rev Biochem Mol Biol 45:535554. CrossRef Medline

Blaustein JD (2012) Steroid hormone receptors: long- and short-term integrators of the internal milieu and the external environment. Horm Metab Res 44:563-568. CrossRef Medline

Bonanni L, Chachar M, Jover-Mengual T, Li H, Jones A, Yokota H, Ofengeim D, Flannery RJ, Miyawaki T, Cho CH, Polster BM, Pypaert M, Hardwick JM, Sensi SL, Zukin RS, Jonas EA (2006) Zinc-dependent multiconductance channel activity in mitochondria isolated from ischemic brain. J Neurosci 26:6851-6862. CrossRef Medline

Brann D, Raz L, Wang R, Vadlamudi R, Zhang Q (2012) Oestrogen signalling and neuroprotection in cerebral ischaemia. J Neuroendocrinol 24: 34-47. CrossRef Medline

Bromberg J, Darnell JE Jr (2000) The role of STATs in transcriptional control and their impact on cellular function. Oncogene 19:2468-2473. CrossRef Medline

Calderone A, Jover T, Noh KM, Tanaka H, Yokota H, Lin Y, Grooms SY, Regis R, Bennett MV, Zukin RS (2003) Ischemic insults de-repress the gene silencer rest in neurons destined to die. J Neurosci 23:2112-2121. Medline

Canal Castro C, Pagnussat AS, Orlandi L, Worm P, Moura N, Etgen AM, Alexandre Netto C (2012) Coumestrol has neuroprotective effects before and after global cerebral ischemia in female rats. Brain Res 1474:82-90. CrossRef Medline

Chen H, Yoshioka H, Kim GS, Jung JE, Okami N, Sakata H, Maier CM, Narasimhan P, Goeders CE, Chan PH (2011) Oxidative stress in ischemic brain damage: mechanisms of cell death and potential molecular targets for neuroprotection. Antioxid Redox Signal 14:1505-1517. CrossRef Medline

Chipuk JE, Moldoveanu T, Llambi F, Parsons MJ, Green DR (2010) The BCL-2 family reunion. Mol Cell 37:299-310. CrossRef Medline

Coremans V, Ahmed T, Balschun D, D'Hooge R, DeVriese A, Cremer J, Antonucci F, Moons M, Baekelandt V, Reumers V, Cremer H, Eisch A, Lagace D, Janssens T, Bozzi Y, Caleo M, Conway EM (2010) Impaired neurogenesis, learning and memory and low seizure threshold associated with loss of neural precursor cell survivin. BMC Neurosci 11:2. CrossRef Medline

De Butte-Smith M, Zukin RS, Etgen AM (2012) Effects of global ischemia and estradiol pretreatment on phosphorylation of Akt, CREB and STAT3 in hippocampal CA1 of young and middle-aged female rats. Brain Res 1471:118-128. CrossRef Medline

Dziennis S, Alkayed NJ (2008) Role of signal transducer and activator of transcription 3 in neuronal survival and regeneration. Rev Neurosci 19: 341-361. Medline

Dziennis S, Jia T, Rønnekleiv OK, Hurn PD, Alkayed NJ (2007) Role of signal transducer and activator of transcription-3 in estradiol-mediated neuroprotection. J Neurosci 27:7268-7274. CrossRef Medline

Eckelman BP, Salvesen GS, Scott FL (2006) Human inhibitor of apoptosis proteins: why XIAP is the black sheep of the family. EMBO Rep 7:988994. CrossRef Medline

Etgen AM, Jover-Mengual T, Zukin RS (2011) Neuroprotective actions of estradiol and novel estrogen analogs in ischemia: translational implications. Front Neuroendocrinol 32:336-352. CrossRef Medline

Gritsko T, Williams A, Turkson J, Kaneko S, Bowman T, Huang M, Nam S, Eweis I, Diaz N, Sullivan D, Yoder S, Enkemann S, Eschrich S, Lee JH, Beam CA, Cheng J, Minton S, Muro-Cacho CA, Jove R (2006) Persistent activation of stat3 signaling induces survivin gene expression and confers resistance to apoptosis in human breast cancer cells. Clin Cancer Res 12:11-19. CrossRef Medline

Gyrd-Hansen M, Meier P (2010) IAPs: from caspase inhibitors to modulators of NF-kappaB, inflammation and cancer. Nat Rev Cancer 10:561574. CrossRef Medline

Hardwick JM, Youle RJ (2009) SnapShot: BCL-2 proteins. Cell 138: 404,e1404.e2. CrossRef Medline

Horvath CM (2000) STAT proteins and transcriptional responses to extracellular signals. Trends Biochem Sci 25:496-502. CrossRef Medline

Iscru E, Ahmed T, Coremans V, Bozzi Y, Caleo M, Conway EM, D’Hooge R, Balschun D (2013) Loss of survivin in neural precursor cells results in 
impaired long-term potentiation in the dentate gyrus and CA1-region. Neuroscience 231:413-419. CrossRef Medline

Jiang Y, de Bruin A, Caldas H, Fangusaro J, Hayes J, Conway EM, Robinson ML, Altura RA (2005) Essential role for survivin in early brain development. J Neurosci 25:6962-6970. CrossRef Medline

Jonas EA, Hickman JA, Hardwick JM, Kaczmarek LK (2005) Exposure to hypoxia rapidly induces mitochondrial channel activity within a living synapse. J Biol Chem 280:4491-4497. Medline

Jover-Mengual T, Zukin RS, Etgen AM (2007) MAPK signaling is critical to estradiol protection of CA1 neurons in global ischemia. Endocrinology 148:1131-1143. Medline

Jover-Mengual T, Miyawaki T, Latuszek A, Alborch E, Zukin RS, Etgen AM (2010) Acute estradiol protects CA1 neurons from ischemia-induced apoptotic cell death via the PI3K/Akt pathway. Brain Res 1321:1-12. CrossRef Medline

Jung JE, Kim GS, Narasimhan P, Song YS, Chan PH (2009) Regulation of Mn-superoxide dismutase activity and neuroprotection by STAT3 in mice after cerebral ischemia. J Neurosci 29:7003-7014. CrossRef Medline

Kelly MJ, Rønnekleiv OK (2012) Membrane-initiated actions of estradiol that regulate reproduction, energy balance and body temperature. Front Neuroendocrinol 33:376-387. CrossRef Medline

Lebesgue D, Chevaleyre V, Zukin RS, Etgen AM (2009) Estradiol rescues neurons from global ischemia-induced cell death: multiple cellular pathways of neuroprotection. Steroids 74:555-561. CrossRef Medline

Liou AK, Clark RS, Henshall DC, Yin XM, Chen J (2003) To die or not to die for neurons in ischemia, traumatic brain injury and epilepsy: a review on the stress-activated signaling pathways and apoptotic pathways. Prog Neurobiol 69:103-142. CrossRef Medline

Liu S, Lau L, Wei J, Zhu D, Zou S, Sun HS, Fu Y, Liu F, Lu Y (2004) Expression of $\mathrm{Ca}(2+)$-permeable AMPA receptor channels primes cell death in transient forebrain ischemia. Neuron 43:43-55. CrossRef Medline

Livak KJ, Schmittgen TD (2001) Analysis of relative gene expression data using real-time quantitative PCR and the 2(-Delta Delta C(T)) Method. Methods 25:402-408. CrossRef Medline

McEwen BS, Akama KT, Spencer-Segal JL, Milner TA, Waters EM (2012) Estrogen effects on the brain: actions beyond the hypothalamus via novel mechanisms. Behav Neurosci 126:4-16. CrossRef Medline

Miyawaki T, Mashiko T, Ofengeim D, Flannery RJ, Noh KM, Fujisawa S, Bonanni L, Bennett MV, Zukin RS, Jonas EA (2008) Ischemic preconditioning blocks $\mathrm{BAD}$ translocation, Bcl-xL cleavage, and large channel activity in mitochondria of postischemic hippocampal neurons. Proc Natl Acad Sci U S A 105:4892-4897. CrossRef Medline

Miyawaki T, Ofengeim D, Noh KM, Latuszek-Barrantes A, Hemmings BA, Follenzi A, Zukin RS (2009) The endogenous inhibitor of Akt, CTMP, is critical to ischemia-induced neuronal death. Nat Neurosci 12:618-626. CrossRef Medline

Moskowitz MA, Lo EH, Iadecola C (2010) The science of stroke: mechanisms in search of treatments. Neuron 67:181-198. CrossRef Medline

Noh KM, Hwang JY, Follenzi A, Athanasiadou R, Miyawaki T, Greally JM, Bennett MV, Zukin RS (2012) Repressor element-1 silencing transcription factor (REST)-dependent epigenetic remodeling is critical to ischemia-induced neuronal death. Proc Natl Acad Sci U S A 109:E962-E971. CrossRef Medline

Ofengeim D, Miyawaki T, Zukin RS (2011) Molecular and cellular mechanisms of ischemia-induced neuronal death. In: Stroke: pathophysiology, diagnosis and management (Mohr JP, Wolf P, Grotta JC, Moskowitz MA, Mayberg M, von Kummer R, eds), pp 75-106. Philadelphia: Churchill Livingstone Elsevier.

Reich NC, Liu L (2006) Tracking STAT nuclear traffic. Nat Rev Immunol 6:602-612. CrossRef Medline

Satriotomo I, Bowen KK, Vemuganti R (2006) JAK2 and STAT3 activation contributes to neuronal damage following transient focal cerebral ischemia. J Neurochem 98:1353-1368. CrossRef Medline

Scott EL, Zhang QG, Han D, Desai BN, Brann DW (2013) Long-term estrogen deprivation leads to elevation of Dickkopf-1 and dysregulation of Wnt/beta-Catenin signaling in hippocampal CA1 neurons. Steroids 78: 624-632. CrossRef Medline

Scott E, Zhang QG, Wang R, Vadlamudi R, Brann D (2012) Estrogen neuroprotection and the critical period hypothesis. Front Neuroendocrinol 33:85-104. CrossRef Medline

Stephanou A, Brar BK, Knight RA, Latchman DS (2000) Opposing actions of STAT- 1 and STAT- 3 on the Bcl-2 and Bcl-x promoters. Cell Death Differ 7:329-330. CrossRef Medline

Suzuki S, Tanaka K, Nogawa S, Dembo T, Kosakai A, Fukuuchi Y (2001) Phosphorylation of signal transducer and activator of transcription-3 (Stat3) after focal cerebral ischemia in rats. Exp Neurol 170:63-71. CrossRef Medline

Turkson J, Ryan D, Kim JS, Zhang Y, Chen Z, Haura E, Laudano A, Sebti S, Hamilton AD, Jove R (2001) Phosphotyrosyl peptides block Stat3mediated DNA binding activity, gene regulation, and cell transformation. J Biol Chem 276:45443-45455. CrossRef Medline

Wen TC, Peng H, Hata R, Desaki J, Sakanaka M (2001) Induction of phosphorylated-Stat 3 following focal cerebral ischemia in mice. Neurosci Lett 303:153-156. CrossRef Medline

Youle RJ, Strasser A (2008) The BCL-2 protein family: opposing activities that mediate cell death. Nat Rev Mol Cell Biol 9:47-59. CrossRef Medline

Zhang QG, Wang R, Khan M, Mahesh V, Brann DW (2008) Role of Dickkopf-1, an antagonist of the Wnt/beta-catenin signaling pathway, in estrogen-induced neuroprotection and attenuation of tau phosphorylation. J Neurosci 28:8430-8441. CrossRef Medline 